\title{
Modelling the effectiveness of enforcement strategies for avoiding tropical deforestation in Kerinci Seblat National Park, Sumatra
}

\author{
Matthew Linkie $\cdot$ Ente Rood $\cdot$ Robert J. Smith
}

Received: 1 September 2009/Accepted: 19 November 2009/Published online: 11 December 2009

(C) The Author(s) 2009. This article is published with open access at Springerlink.com

\begin{abstract}
As the tropical deforestation crisis continues, innovative schemes are being developed to reduce this loss, such as the sale of forest carbon credit. Nevertheless, to address this ongoing and pervasive loss, governments, protected area managers and donors need to know where to invest their limited conservation resources for greatest success. At the moment this prioritisation is rarely done objectively, so there is a need for new methods that predict the efficacy of different approaches. In this study, we focus on forest loss in and around one of Indonesia's largest protected areas, Kerinci Seblat National Park (KSNP), and evaluate the effectiveness of several forest protection scenarios. First, forest loss patterns from 1985 to 2002 were mapped for the southern end of the KS region and the correlates of deforestation were determined using a logistic regression analysis. This highlighted the critical threat posed to the forest by its proximity to the forest edge and to settlements, as well as its elevation and slope. This regression model was then used to map the predicted risk of remaining forest being cleared and was combined with field data to model the results of three law enforcement scenarios up to the year 2020. This found that a strategy that concentrated patrol effort at the four main access points was found to avoid the most deforestation. These results show that modelling the impact of different protection
\end{abstract}

\footnotetext{
M. Linkie $(\bowtie)$

Fauna \& Flora International, Indonesia Programme, Banda Aceh, Nanggroe Aceh Darussalam, Indonesia

e-mail: matthew.linkie@ffi.or.id

E. Rood

Zoological Museum, University of Amsterdam, Mauritskade 61, 1092 AD Amsterdam,

The Netherlands

E. Rood

Department of Anthropology and Geography, Oxford Brookes University, Gipsy Lane,

Oxford OX3 0BP, UK
}

R. J. Smith

Durrell Institute of Conservation and Ecology, University of Kent, Canterbury, Kent CT2 7NR, UK 
strategies can provide important insights and could be used more widely in deforestation mitigation and designing conservation landscapes.

Keywords Conservation planning - Indonesia - Law enforcement - Logistic regression · REDD · Threat · Vulnerability

\section{Introduction}

Despite substantial international funding to protect rainforests, global deforestation rates show little sign of abatement, suggesting that previous efforts have generally had limited success (Whitten et al. 2002). Whilst the ongoing loss of tropical rainforests represents one of the most serious threats to biodiversity (Sodhi and Brook 2008), recent discussions on tropical deforestation have focussed on its contribution to climate change (Kanninen et al. 2007). Failure to avoid this deforestation is predicted to greatly accelerate global warming by releasing $>87$ billion metric tons of greenhouse gases into the atmosphere by 2100 (Gullison et al. 2007). In response, forest conservation initiatives are considering policy approaches for 'reducing emissions from deforestation and degradation' (REDD), which essentially pays governments to reduce deforestation below an estimated background rate.

The performance of avoided deforestation schemes currently remains untested as no projects have generated carbon revenue. However, these schemes are likely to prove useful in supporting and further strengthening traditional conservation strategies, especially through increased funding for protected area management. At a national level, protected area networks have been shown to avoid significantly more tropical deforestation than unprotected areas (Andam et al. 2008; Gaveau et al. 2009). Within these and other areas, law enforcement is likely to be the principal management strategy that explains most of the avoided forest loss (Abbot and Mace 1999). For this strategy to be effective, patrols should not be spread too thinly (Leader-Williams and Albon 1988) but, instead, focused on the most vulnerable areas, identified from their correlates of deforestation.

Tropical deforestation tends to be driven by the expansion of agricultural frontiers, such as oil palm (Wilcove, in press), and unsustainable logging practices, which are typically related to accessibility, such as forest proximity to roads and elevation (Linkie et al. 2004; Gaveau et al. 2009). Consequently, the lowland forests, which have the highest levels of biodiversity and carbon storage capacity, are highly threatened because they contain high quality timber and tend to be most accessible (Jepson et al. 2001; Laurance et al. 2009). Thus, research on the investment of conservation resources is particularly relevant for tackling deforestation because increasing protection in the most accessible areas might not only provide direct benefits to these threatened forests, but also act as a barrier to preventing further forest loss (Peres and Terborgh 1995). However, the evaluation of the performance of law enforcement strategies through spatial modelling has received little attention.

Here, we focus on conservation management intervention in and around the southern section of KSNP. Firstly, we statistically determine the drivers of deforestation and then use these to model deforestation patterns in the absence of active forest protection. Secondly, we investigate the impact of a constant law enforcement effort that is allocated to protecting the: largest remaining patches of lowland forest; and, most vulnerable patches of forest. 


\section{Methods}

Study area

The 13,300 km² UNESCO World Heritage Site of KSNP covers four Sumatran provinces (Bengkulu, Jambi, South Sumatra and West Sumatra). The broad forest types, which in many places extend outside of the KSNP border, range from lowland (0-300 $\mathrm{m}$ a.s.1.) to hill (300-800 m), submontane (800-1400 m) and montane (1400 m+). This study focuses on the $4278 \mathrm{~km}^{2}$ forest located within the Bengkulu section of KSNP, which contains the majority of the KS lowland forest, considered as a unique eco-floristic sector that is 'Vulnerable' to extinction (Laumonier et al., submitted). This lowland forest consists of two contiguous patches that straddle the KSNP border.

Species-based law enforcement patrol units, that have been operating elsewhere in the KS region since 2001, were recently established for Bengkulu. Whilst the primary focus of the forest patrols is, currently, to remove snare traps set for tiger and their ungulate prey, efforts to tackle forest habitat loss are to receive greater attention, and so information on where to intervene and the predicted impact of the intervention would greatly assist these units.

\section{Remote sensing and GIS data}

To determine the locations and rates of deforestation (defined as complete forest conversion to farmland), forest cover from 1985, 1995, 2002 and 2004 was mapped across the KS-Bengkulu section. Six Landsat MSS, TM and ETM + images (WRSII path/row: 126/ 062) were resampled to a resolution of $100 \mathrm{~m}$ within ArcView v3.2 GIS software package (ESRI Inc., Redlands, CA). All images were geometrically corrected (using the UTM-47s coordinate system) to accurately represent the land-cover on the ground and radiometrically corrected to remove the effects of atmospheric haze. A false colour composite image was produced for each image by combining bands 5, 4 and 2 in this order. The forest change map was then constructed by using an on-screen digitizing method to map forest and non-forest classes from the different years. The accuracy of the 2004 map was groundtruthed in the field at 100 points that were randomly selected within sites where the land cover type was not known (subsequently, $91 \%$ of these points were found to be correctly classified).

To investigate deforestation risk, a GIS dataset that contained four spatial covariates (elevation, slope, distance to forest edge and distance to nearest settlement) was produced, as these covariates all relate to accessibility. A road layer was excluded form the analysis because of its strong correlation $(P<0.001)$ with proximity to the forest edge $\left(r_{\mathrm{s}}=0.405\right)$ and to settlements $\left(r_{\mathrm{s}}=0.335\right)$. The digital elevation model data were obtained from the Shuttle Radar Topography Mission (Rabus et al. 2003), which was then used to produce the slope layer. The forest edge information was taken from the 2002 forest cover classification. The position of settlements was obtained from 1:50,000 maps produced by Indonesian National Coordination Agency for Surveys and Mapping. All of these coverages were converted to a $100 \mathrm{~m}^{2}$ resolution raster format.

Spatial statistics

The forest risk model was determined using data from 200 forested points that were cleared between 1995 and 2002 and another 200 points that remained forested during this period. 
Each set of points was randomly selected using the ArcView Animal Movement extension, but with a constraint that they must be more than $2 \mathrm{~km}$ apart, to reduce the likelihood of spatial autocorrelation. The GIS was then used to extract the physical covariates values at each of the 400 points. These spatial variables were imported into SPSS v.11 statistical software package (SPSS Inc., Chicago, IL) and transformed to prevent outliers from having a disproportionate influence on the analysis. Next, a Spearman's rank correlation was conducted to test for collinearity between the four spatial covariates. Non-independence was identified between slope and elevation, so a data reduction technique (PCA) was performed. This produced two components (with eigenvalues of 0.3532 and 0.0511 , respectively) that were then used in subsequent analyses, instead of the original covariates.

Logistic regression analyses were performed to determine which covariates, individually and in combination, best explained deforestation across the study area. Models were compared on the basis of the Akaike Information Criterion (AIC) and Akaike weights $\left(w_{i}\right)$ (Burnham and Anderson 2002). Models that were within two AIC units ( $\triangle \mathrm{AIC}$ ) of the top ranked model with the smallest AIC were considered as plausible candidate models and their results discussed. The performance of a final regression model was then evaluated by calculating the area under the curve of receiver operating characteristics (ROC) plots. The presence of spatial autocorrelation in the model was then tested by calculating Moran's I statistic (Cliff and Ord 1981) using the Crime-Stat v1.1 software package (N Levine and Associates, Annadale, VA).

Next, a spatially explicit forest risk model was constructed within the GIS, using the significant spatial covariates and their beta coefficient values within the final logistic regression equation. A Mann-Whitney $U$ test was performed to investigate the accuracy of the deforestation risk model. For this, the mean predicted risk values were extracted for 100 randomly selected points that were cleared between 2002 and 2004 and compared with 100 randomly selected points that had not been cleared during the same period.

\section{Modeling conservation intervention scenarios}

Based on the amount of remaining forest cover in 2002, the 1985-2002 deforestation rate was recalculated as the area of forest predicted to be cleared in the following year (i.e. 2003). Next, to predict and map deforestation patterns across the study area, a three stage iterative process was performed. First, the most threatened forest patches ( 1 ha pixels) equivalent to the calculated area of forest loss were identified and removed from the forest risk model. Second, this forest loss was then incorporated within an updated distance to forest edge covariate which, along with the other spatial covariates, formed a revised spatial dataset. The revised distance to edge layer, which moved further into the interior of the study area, had the effect of increasing the accessibility (and therefore risk value) of forest pixels close to the new edge boundary. Third, an updated deforestation model for the next year was constructed by performing a logistic regression analysis on the updated spatial dataset to then produce a forest risk model for the following year. This iterative process was performed yearly until 2020 .

For all years modelled, a deforestation threshold was included within the modelling procedure. This threshold reflects the net cost of deforestation and was based on the lowest predicted deforestation probability that was found to be cleared between 1985 and 2002. This meant that forest pixels with a risk value equal to or lower than the threshold could not be cleared within the modelling procedure, thereby reflecting a realistic situation on the ground, because deforestation rates would reduce over time as forest less suitable for clearance, e.g. at higher elevations, would not be cleared at the same rate as the more 
susceptible forest patches. This modelling procedure represented a scenario (\#1) for no active conservation intervention. Next, the iterative deforestation modelling process was performed to determine the impact of two additional conservation intervention scenarios.

The subsequent scenarios were modelled using data derived from the forest patrol patterns (i.e. $476 \mathrm{~km}^{2}$ forest covered) of the Bengkulu ranger law enforcement unit from 2007 , the year in which the units became fully operational in the study area. Scenario \#2 modelled the investment of $476 \mathrm{~km}^{2}$ of full protection on the two largest lowland patches. Deforestation probabilities over these two areas were masked so that they could not be cleared. This also created a cost barrier, whereby interior forest lying behind these masks became less accessible as loggers would have to move around the fully protected patches rather than through them. Scenario \#3 modelled $476 \mathrm{~km}^{2}$ of full protection on the four most threatened patches, as identified by the forest risk model from Scenario \#1.

\section{Results}

Spatio-temporal deforestation patterns

Between 1985 and 2002, an average deforestation rate of $1.41 \% / \mathrm{yr}$ was recorded in the Bengkulu study area. The most rapidly cleared forest type was lowland (3.18\%/yr), followed by submontane $(0.74 \% / y r)$, hill $(0.53 \% / y r)$ and then montane $(0.04 \% / y r)$. Deforestation was related to forest accessibility, with forest closer to settlements, to forest edge, at lower elevations and on flatter land being more likely to be cleared for farmland (Table 1). The final regression model (\#1.1) explained $76.8 \%$ of the original observations, was not affected by spatial autocorrelation (Moran's $I=-0.005, P>0.1$ ) and had an ROC value of $0.849 \pm 0.021$, indicating a highly accurate model fit. The spatially explicit forest risk model (Fig. 1), which was based on the results of the final regression model (Table 1), was found to accurately predict deforestation that occurred between 2002 and 2004 (cleared predicted probability; $0.5031 \pm 0.2024,1 \mathrm{SD}$, uncleared predicted probability; $0.2167 \pm 0.1933$, Mann-Whitney $U$ test: $Z=-8.725, P<0.001)$. From the final model a deforestation risk threshold of $P=0.85$ was identified and used in the subsequent scenario modelling.

Table 1 Logistic regression model describing the relationships between landscape variables and deforestation patterns across the Bengkulu region of Kerinci Seblat, Sumatra

\begin{tabular}{llllll}
\hline Model $^{\text {a }}$ & $\begin{array}{l}2 \text { log } \\
\text { likelihood }\end{array}$ & $K$ & $\Delta$ AIC & $w_{i}$ & $r^{2}$ \\
\hline 1.1. Dist. Forest Edge + Dist. Settle + Comp1 + Comp2 & 386.41 & 5 & 0.00 & 0.901 & 0.458 \\
1.2. Dist. Forest Edge + Dist. Settle + Comp1 & 392.85 & 4 & 4.44 & 0.098 & 0.443 \\
1.3. Dist. Forest Edge + Comp1 + Comp2 & 402.52 & 4 & 14.11 & 0.001 & 0.422 \\
1.4. Dist. Forest Edge + Comp1 & 409.93 & 3 & 19.52 & 0.000 & 0.404 \\
1.5. Dist. Settle + Comp1 + Comp2 & 422.37 & 4 & 33.96 & 0.000 & 0.375 \\
1.6. Dist. Forest Edge + Dist. Settle & 439.10 & 3 & 48.69 & 0.000 & 0.334 \\
1.7. Dist. Forest Edge & 449.06 & 2 & 56.65 & 0.000 & 0.309 \\
1.8. Dist. Settle & 503.85 & 2 & 111.44 & 0.000 & 0.159 \\
\hline
\end{tabular}

a Comp1 and Comp2 contain PCA information from elevation and slope covariates 


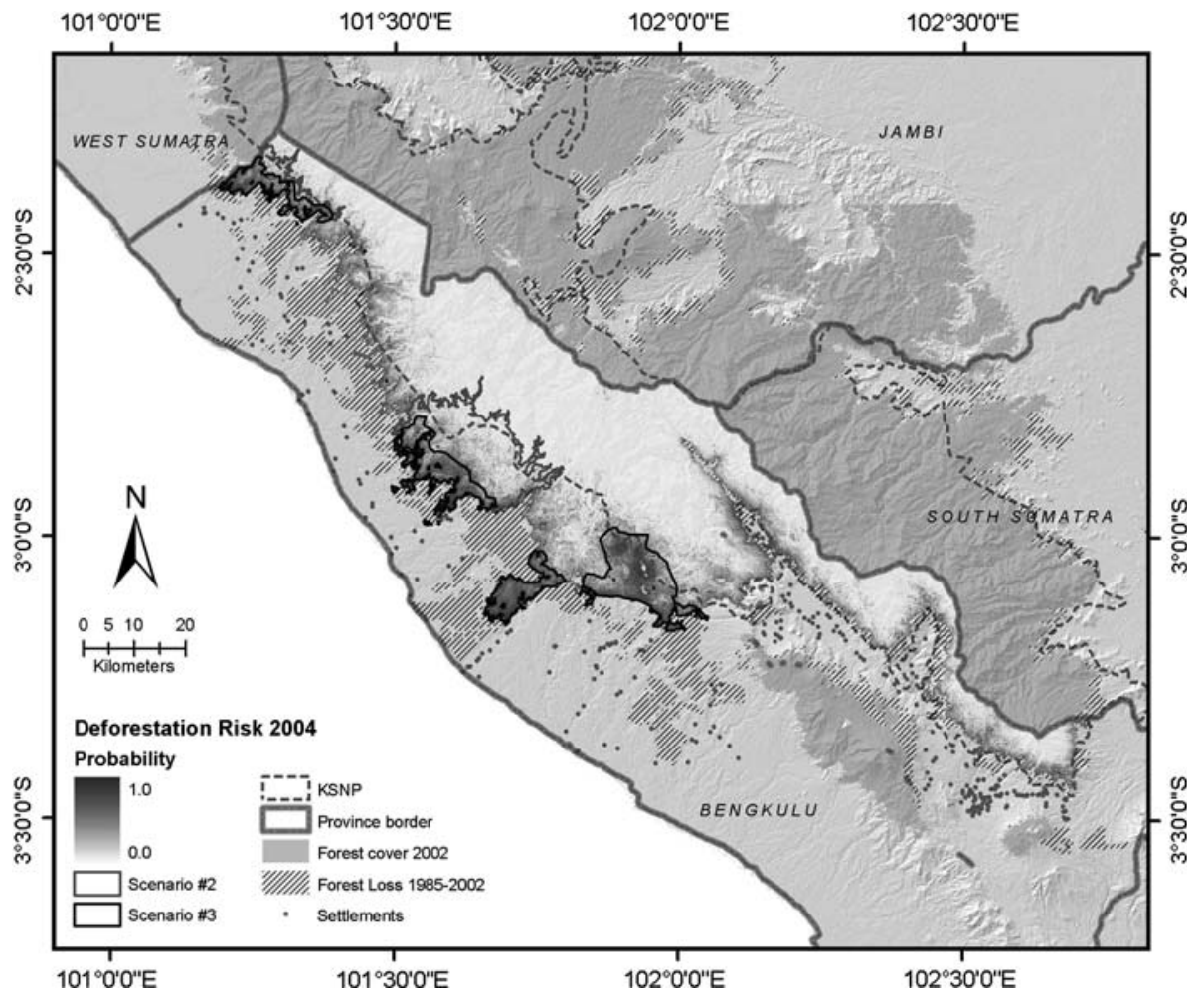

Fig. 1 Predicted forest risk in the Bengkulu province section of Kerinci Seblat National Park (KSNP) and surrounding areas and allocation of law enforcement effort for two active protection scenarios

Conservation intervention strategies

Scenario \#1, which modelled forest loss patterns in the absence of active protection, highlighted the critical risk posed to all lowland forest, which was predicted to be cleared much quicker than the other forest types because of its greater accessibility (Fig. 2). Focusing protection on the two largest lowland forest patches (Scenario \#2) was effective in reducing the loss of this forest type and, by the year $2020,82 \%$ of the lowland forest was predicted to remain. However, this remaining forest only comprised the two forest patches that were under strict protection, with the majority of the other lowland forest having disappeared by 2010 .

The greatest forest protection gains were derived from an intervention strategy that focussed on the four most threatened forest patches (Scenario \#3). This strategy had the effect of securing the most accessible forest blocks and provided wider indirect benefits to the interior forests that were predicted to have been cleared, in the absence of active intervention (Fig. 2). Under this scenario, $97 \%$ of the lowland forest was predicted to remain by the year 2020 .

Finally, comparing the different patterns of law enforcement investment revealed that by cutting off the main access points, i.e. protecting the four most threatened blocks, had the most noticeable difference in reducing the deforestation rates and the model predicted immediate benefits from this investment (Fig. 3). Deforestation rates in Scenario \#3 
Fig. 2 The proportion of total forest loss and lowland forest loss under different law enforcement scenarios $(\# 1=$ no active protection, \#2 = active protection on the two largest lowland forest patches and $\# 3=$ active protection on the four most threatened forest blocks)
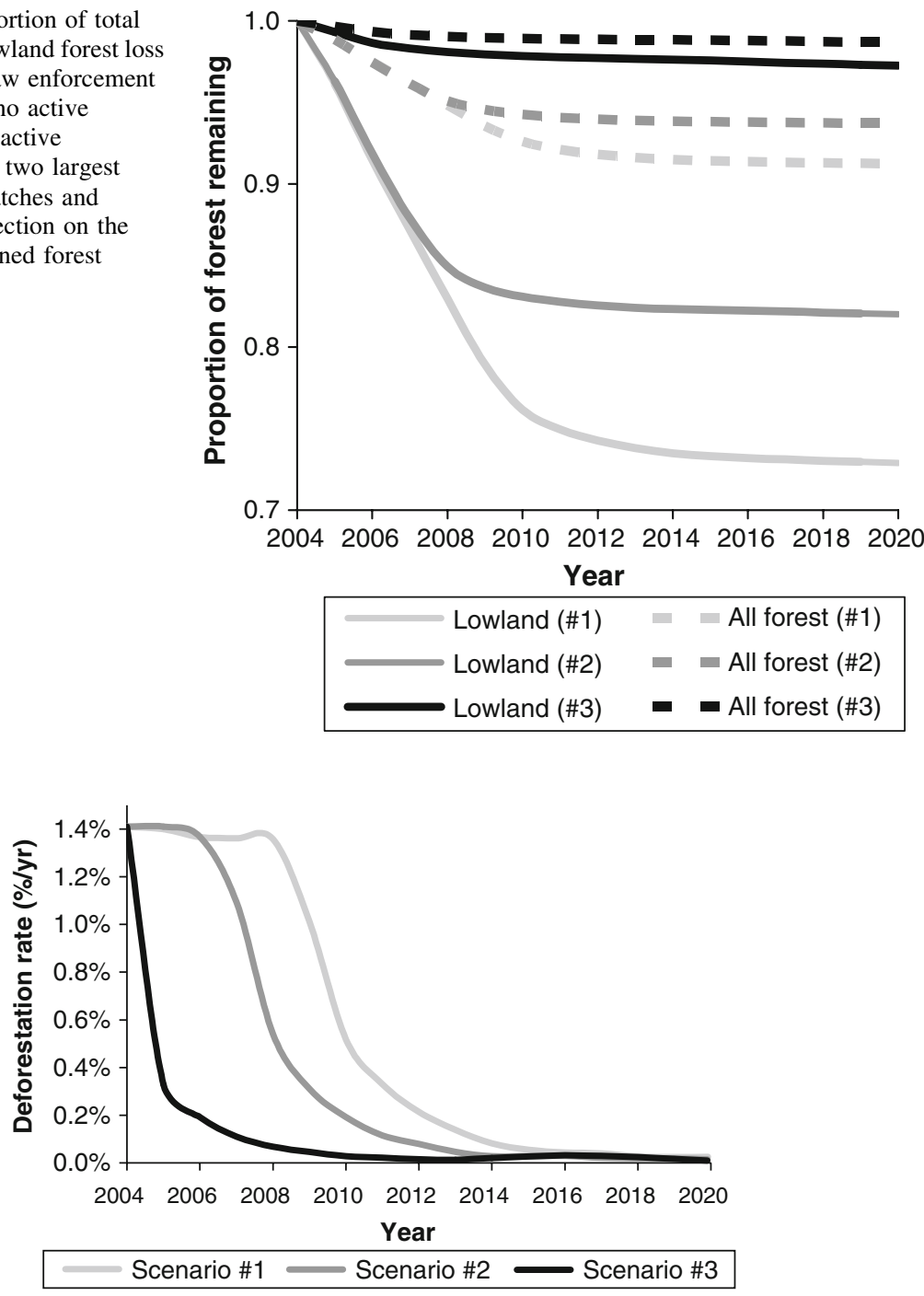

Fig. 3 Deforestation rates under different law enforcement scenarios $\# 1=$ no active protection, $\# 2$ = active protection on the two largest lowland forest patches and \#3 = active protection on the four most threatened forest blocks)

reduced to their minimum $(0.01 \% / y r)$ by 2010 , while for the other scenarios this occurred by 2020 .

\section{Discussion}

Sumatra has some of the highest levels of forest loss in the tropics, a fact that has been extensively documented in the peer-reviewed conservation literature, along with its detrimental impact on components of Sumatran biodiversity (e.g. Achard et al. 2002; Gaveau 
et al. 2007; Hedges et al. 2005; Kinnaird et al. 2003; Linkie et al. 2004, 2006). Despite such a large body of research, there are very few solutions on how to reverse these deforestation trends and species threats (Gaveau et al. 2009; Linkie et al. 2008). From the spatially explicit modelling technique developed in this study, we found that it was possible to gain important insights on the impact of different conservation investment scenarios. From this, our models showed that a law enforcement strategy aimed at cutting off the four main access points into the forest was predicted to avoid the most deforestation, both temporally and spatially, for which the implications are discussed below.

\section{Temporal deforestation patterns}

The government sponsored and spontaneous transmigrations from Java to the southern parts of Sumatra in the 1970s and 1980s led to massive amounts of forest being converted to small-scale farmland. The deforestation pattern spread from the east, where most transmigrants initially settled, to the west and then north to Bengkulu (Gaveau et al. 2007; Linkie et al. 2008). This historical trend partly explains the notably higher deforestation rate in the Bengkulu study area (1.41\%/yr) compared to the surrounding KS region $(1.02 \% /$ yr). However, Bengkulu also contains the largest patches of lowland forest in the KS region, which came under great pressure in the late 1990s during the decentralisation of the Indonesian natural resource sector.

The decentralisation process led to high and unprecedented levels of illegal logging in Sumatra, to which the KS region was not immune (McCarthy 2002; Jepson et al. 2001). This illegal logging typically involved the selective removal of high quality timber trees for export, rather than the conversion of forest for farmland that were mapped in our analysis. Our deforestation estimates did not include the forest degradation caused by illegal timber trade and therefore represent a conservative estimate of the degradation. Nevertheless, with the removal of the most accessible export-quality timber from our study area, many loggers would have turned their attention back to agriculture (e.g. smallscale farming or plantations), thereby contributing to the inflated Bengkulu deforestation rate.

\section{Spatial deforestation patterns}

The spatial patterns of deforestation across the KS region highlighted the critical role of accessibility, with the importance of distance to forest edge, distance to settlements and suitable terrain being expected, given the results from previous studies (Trejo and Dirzo 2000; Laurance et al. 2002). This also explained why submontane forest, which was located closer to the forest edges and to settlements than hill forest, tended to be at a greater risk to clearance than hill forest, which seems to have been initially buffered by the location of lowland forest (Scenario \#1).

In the KS region, deforestation levels were generally higher around settlements, presumably because villagers preferred to travel shorter distances to clear areas for farmland. However, most of these settlements were at lower elevations and so the net effect of this was that low-lying forest was most susceptible to clearance. Whilst this emphasises the importance of providing alternative livelihood opportunities and tangible incentives for local communities to reduce illegal logging and overexploitation (Linkie et al. 2008), part of any solution will involve active forest protection. The deforestation models developed in this study identified where to focus such protection for best results. 
Conservation intervention strategies

Few studies have modelled the effectiveness of law enforcement in mitigating forest clearance. For KSNP, and most other Indonesian protected areas, protection strategies are rarely based on models that identified the areas most susceptible to threats, because such predictive information tends to be lacking. From the different protection scenarios, we found that a strategy aimed at concentrating ranger patrol effort in the four most vulnerable forest locations, rather than in fewer larger forest patches, was predicted to offset the most forest loss.

Preventing entry to the forest by blocking the main access points is sensible as it should increase the costs associated with clearance, e.g. travel time to market from the location. Such a strategy is also anticipated to increase the probability of encroachers being detected which, for wildlife protection, has been shown to act as a greater deterrent in mitigating illegal activities, such as poaching, than indirect intervention, such as fines or protected area status (Leader-Williams et al. 1990; Rowcliffe et al. 2004). We found that the KSNP status may have acted as a deterrent because more deforestation occurred outside of the park border than inside.

The view that even poorly funded protected areas can be partially effective has been supported by findings based on questionnaire data (Bruner et al. 2001). However, caution is needed when interpreting this result from KSNP, as in other protected areas (Liu et al. 2001) because KSNP contains a large amount of inaccessible forest and its designation was partly based on its unsuitability for other land uses. In addition, there are still patches of forest outside of KSNP that can be logged without breaking the laws specifically associated with protected areas, which enable the law enforcement units to make arrests. These factors, in combination, suggest that deforestation inside the protected area is likely to occur at a slower rate than elsewhere. Nevertheless, logging was still found to take place within KSNP when no other sources of timber or space for farmland were available. If KSNP was effective in preventing the spread of illegal logging, then there would have been no deforestation within the PA and this was clearly not the case as illustrated by the 19852002 forest loss patterns.

\section{Method validation}

The value of our conclusions should be set in the context of possible limitations of the modelling framework used. Deforestation patterns were modelled based on knowledge of historical patterns across the region and therefore assumed that future deforestation processes would progress at the same rate as observed over the ensuing 20 years. Whilst it was not possible for the models to account for any increases in deforestation rates, the incorporation of a deforestation threshold did enable the models to limit clearance in the most remote areas. The spatio-temporal deforestation patterns across southern and central Sumatra, similarly, show that submontane and montane areas are less likely to be converted to farmland, even after they become accessible, as farmers will tend to search for unoccupied lower lying areas (Gaveau et al. 2007; Linkie et al. 2008).

The correlates of deforestation may change over time and, so, the spatial model should be periodically updated to reflect these changes. In our models, this was partially controlled for through the construction of revised distance to forest edge covariate after each annual forest loss stage. Nevertheless, the goodness of fit values $\left(r^{2}\right)$ obtained from the regression analyses showed that these models did not explain all of the variation and that model goodof-fit could have been improved through the incorporation of additional covariates. 
For conservation areas with detailed law enforcement data, it would be interesting to focus on the funds required to deter loggers per $\mathrm{km}^{2}$ and whether this investment changes with increased accessibility. In addition, for conservation areas that are able to determine how their financial investments translate into action on the ground, different scenarios could be run based on varying budget allocations. For example, presumably it is cheaper to patrol a smaller number of clumped patches than lots that are far apart or far from a patrol unit's headquarter. Finally, the protection scenarios presented in this study assigned full protection to the focal patrol areas through a minimum risk threshold value. Even though such generalizations are useful to study the effect of different intervention strategies, this could be enhanced through modelling the gradual effects of forest patrols and spatial shifts in deforestation pressure resulting from intervention strategies.

\section{Conclusion}

The modelling approach developed by this study can operate at three broad levels. Regionally, it could form part of a management system that informs action on the ground, e.g. prioritising conservation effort to at risk areas, and then quantitatively assesses whether these interventions have reduced deforestation (Clements et al., submitted). Nationally, the modelling technique would benefit conservation planning as it enables the incorporation of a vulnerability layer (Wilson et al. 2005, 2006; Smith et al. 2008).

It also has great potential for assisting in the designation of protected area networks and other conservation landscapes, as similar models could be used to determine the order in which protected areas should be established (Pressey et al. 2007). Internationally, the models could inform avoided deforestation schemes, such as REDD, on baseline deforestation scenario models, a prerequisite for carbon audit validations, and then be used to monitor future forest loss patterns. Finally, this combined technique of modelling forest loss and prevention, responds in part to the wider calls for measuring the effectiveness of conservation strategies using robust statistical models (Linkie and Smith 2009).

Acknowledgements We are grateful to Ir. Suyatno, the Indonesian Department of Forestry and Nature Protection and Debbie Martyr, the latter provided information on the KS-law enforcement patrols. We would like to thank Navjot Sodhi and Lian Pin Koh for inviting us to write this article.

Open Access This article is distributed under the terms of the Creative Commons Attribution Noncommercial License which permits any noncommercial use, distribution, and reproduction in any medium, provided the original author(s) and source are credited.

\section{References}

Abbot JIO, Mace R (1999) Managing protected woodlands: fuelwood collection and law enforcement in Lake Malawi National Park. Conserv Biol 13:418-421

Achard F, Eva HD, Stibig HJ, Mayaux P, Gallego J, Richards T, Malingreau JP (2002) Determination of deforestation rates of the world's humid tropical forests. Science 297:999-1002

Andam KS, Ferraro PJ, Pfaff A, Sanchez-Azofeifa GA, Robalino JA (2008) Measuring the effectiveness of protected area networks in reducing deforestation. PNAS 105:16089-16094

Bruner AG, Gullison RE, Rice RE, da Fonseca GAB (2001) Effectiveness of parks in protecting tropical biodiversity. Science 291:125-128

Burnham KP, Anderson DR (2002) Model selection and multimodel inference: a practical informationtheoretic approach, 2nd edn. Springer-Verlag, New York, NY 
Clements R, Rayan DM, Zafir AWA, Venkataraman A, Alfred R, Payne J (submitted) Trio under threat: can we secure the future of rhinos, elephants and tigers in Malaysia? Biodivers Conserv

Cliff AD, Ord JK (1981) Spatial processes-models and applications. Pion, London

Gaveau DLA, Wandono H, Setiabudi F (2007) Three decades of deforestation in southwest Sumatra: have protected areas halted forest loss and logging, and promoted re-growth? Biol Conserv 134:495-504

Gaveau DLA, Epting J, Lyne O, Linkie M, Kumara I, Kanninen M, Leader-Williams N (2009) Evaluating whether protected areas reduce tropical deforestation in Sumatra. J Biogeogr 36:2165-2175

Gullison RE, Frumhoff PC, Canadell JG, Field CB, Nepstad DC, Hayhoe K, Avissar R, Curran LM, Friedlingstein P, Jones CD, Nobre C (2007) Tropical forests and climate policy. Science 316:985-986

Hedges S, Tyson MJ, Sitompul AF, Kinnaird MF, Gunaryadi D, Aslan (2005) Distribution, status, and conservation needs of Asian elephants (Elephas maximus) in Lampung Province, Sumatra, Indonesia. Biol Conserv 124:35-48

Jepson P, Jarvie JK, MacKinnon K, Monk KA (2001) The end for Indonesia's lowland forests? Science 292:859-861

Kanninen M, Murdiyarso D, Seymour F, Angelsen A, Wunder S, German L (2007) Do trees grow on money?: the implications of deforestation research for policies to promote REDD. For Perspect 4:61

Kinnaird MF, Sanderson EW, O'Brien TG, Wibisono HT, Woolmer G (2003) Deforestation trends in a tropical landscape and implications for endangered large mammals. Conserv Biol 17:245-257

Laumonier Y, Uryu Y, Stüwe M, Budiman A, Setiabudi B, Hadian O (submitted) Eco-floristic sectors and deforestation threats in Sumatra: identifying new conservation area network priorities for ecosystembased land use planning. Biodivers Conserv

Laurance WF, Albernaz AKM, Schroth G, Fearnside PM, Bergen S, Venticinque EM, da Costa C (2002) Predictors of deforestation in the Brazilian Amazon. J Biogeogr 29:737-748

Laurance WF, Goosem M, Laurance SGW (2009) Impacts of roads and linear clearings on tropical forests. Trends Ecol Evol 24:659-669

Leader-Williams N, Albon SD (1988) Allocation of resources for conservation. Nature 336:533-535

Leader-Williams N, Albon SD, Berry PSM (1990) Illegal exploitation of black rhinoceros and elephant populations-patterns of decline, law-enforcement and patrol effort in Luangwa Valley, Zambia. J Appl Ecol 27:1055-1087

Linkie M, Smith RJ (2009) Measuring the effectiveness of conservation spending. In: Sodhi N, Ehrlich PR (eds) Conservation biology for all. Oxford University Press, Oxford

Linkie M, Smith RJ, Leader-Williams N (2004) Mapping and predicting deforestation patterns in the lowlands of Sumatra. Biodivers Conserv 13:1809-1818

Linkie M, Chapron G, Martyr DJ, Holden J, Leader-Williams N (2006) Assessing the viability of tiger subpopulations in a fragmented landscape. J Appl Ecol 43:576-586

Linkie M, Smith RJ, Zhu Y, Martyr DJ, Suedmeyer E, Pramono J, Leader-Williams N (2008) Evaluating biodiversity conservation around a large Sumatran protected area. Conserv Biol 22:683-690

Liu J, Linderman M, Ouyang Z, An L, Yang J, Zhang H (2001) Ecological degradation in protected areas: the case of Wolong Nature Reserve for giant pandas. Science 292:98-101

McCarthy JF (2002) Turning in circles: district governance, illegal logging, and environmental decline in Sumatra, Indonesia. Soc Nat Resour 15:867-886

Peres CA, Terborgh JW (1995) Amazonian nature reserves: an analysis of the defensibility status of existing conservation units and design criteria for the future. Conserv Biol 9:34-46

Pressey RL, Cabeza M, Watts ME, Cowling RM, Wilson KA (2007) Conservation planning in a changing world. Trends Ecol Evol 22:583-592

Rabus B, Eineder M, Roth A, Bamler R (2003) The shuttle radar topography mission-a new class of digital elevation models acquired by spaceborne radar. J Photogramm Remote Sens 57:241-262

Rowcliffe JW, de Merode E, Cowlishaw G (2004) Do wildlife laws work? Species protection and the application of a prey choice model to poaching decisions. Proc R Soc Lond B 271:2631-2636

Smith RJ, Easton J, Nhancale BA, Armstrong AJ, Culverwell J, Dlamini S, Goodman PS, Loffler L, Matthews WS, Monadjem A, Mulqueeny CM, Ngwenya P, Ntumi CP, Soto B, Leader-Williams N (2008) Designing a transfrontier conservation landscape for the Maputaland centre of endemism using biodiversity, economic and threat data. Biol Conserv 141:2127-2138

Sodhi N, Brook BW (2008) Fragile Southeast Asian biotas. Biol Conserv 141:883-884

Trejo I, Dirzo R (2000) Deforestation of seasonally dry tropical forest: a national and local analysis in Mexico. Biol Conserv 94:133-142

Whitten T, Holmes D, MacKinnon K (2002) Conservation biology: a displacement behavior for academia? Conserv Biol 15:1-3

Wilcove DS (in press) Addressing the threats to biodiversity from oil palm agriculture. Biodivers Conserv 
Wilson K, Pressey RL, Newton A, Burgman M, Possingham HP, Weston CJ (2005) Measuring and incorporating vulnerability into conservation planning. Environ Manag 35:527-543

Wilson KA, McBride MF, Bode M, Possingham HP (2006) Prioritising global conservation efforts. Nature 440:337-340 